\title{
Phasor Measurement Unit under Interference Conditions
}

\author{
Ghiga, Radu; Martin, Kenneth E.; Wu, Qiuwei; Nielsen, Arne Hejde
}

Published in:

IEEE Transactions on Power Delivery

Link to article, DOI:

10.1109/TPWRD.2017.2691356

Publication date:

2017

Document Version

Peer reviewed version

Link back to DTU Orbit

\section{Citation (APA):}

Ghiga, R., Martin, K. E., Wu, Q., \& Nielsen, A. H. (2017). Phasor Measurement Unit under Interference Conditions. IEEE Transactions on Power Delivery, 33(2), 630 - 639.

https://doi.org/10.1109/TPWRD.2017.2691356

\section{General rights}

Copyright and moral rights for the publications made accessible in the public portal are retained by the authors and/or other copyright owners and it is a condition of accessing publications that users recognise and abide by the legal requirements associated with these rights.

- Users may download and print one copy of any publication from the public portal for the purpose of private study or research.

- You may not further distribute the material or use it for any profit-making activity or commercial gain

- You may freely distribute the URL identifying the publication in the public portal 


\title{
Phasor Measurement Unit Test under Interference Conditions
}

\author{
Radu Ghiga, Student Member, IEEE, Kenneth Martin, Fellow, IEEE, Qiuwei Wu, Senior Member, \\ IEEE, and Arne Hejde Nielsen, Senior Member, IEEE
}

\begin{abstract}
This paper investigates the performance of Phasor Measurement Units (PMUs) under interference conditions which can appear in a power system and are not tested by the C37.118.1 standard. Three PMUs from different vendors configured for the M-class requirements were used to test three possible interference condition scenarios. In the first scenario, noise is added to the PMU input signal. The test runs a sweep of Signalto-Noise Ratios (SNR) and the accuracy versus the noise level is obtained. The second scenario injects multiple harmonics with the input to test the influence on accuracy. The last scenario focuses on instrument transformer saturation which leads to a modified waveform injected in the PMU. This test goes through different levels of Current Transformer (CT) saturation and analyzes the effect of saturation on the accuracy of PMUs. The test results show PMU measurements will be degraded when the input signal is distorted by high noise or a saturated current waveform, but is not particularly affected by multiple harmonics. This information can be used when selecting a PMU to ensure it will provide a reliable measurement for the intended use. It can also be used for developing more robust PMUs and applications resistant to degraded measurements.
\end{abstract}

Index Terms - Interference conditions, Phasor Measurement Unit (PMU), PMU testing.

\section{INTRODUCTION}

$\mathrm{T}$ he performance of Phasor Measurement Units (PMU) has been a topic of high interest in recent years. The generalized synchrophasor definitions and compliance under steady-state and dynamic conditions are provided in the IEEE C37.118.1-2011 standard [1] and IEEE C37.118.1a-2014 amendment [2]. An IEEE Test Suite Specification guide for testing and calibrating PMUs with a greater level of uniformity is now available [3]. Substantial work has been carried out in implementing test platforms and verifying the compliance under [1] and [2] of commercial PMUs [4]-[7]. These studies determined that most of these devices are not compliant with the dynamic requirements. The classic synchrophasor measurement methods are Discrete Fourier Transform (DFT)-based. While they have a low computation burden, the accuracy of these methods show degraded

The work was supported by the Nordic Energy Research (Norden) which supports the Smart transmission grid operation and control (StronGrid) project.

R. Ghiga, Q. Wu and A. H. Nielsen are with the Center for Electric Power and Energy (CEE), Department of Electrical Engineering, Technical University of Denmark (DTU), Kgs. Lyngby, 2800, Denmark (e-mail: rghiga@elektro.dtu.dk, qw@elektro.dtu.dk, ahn@elektro.dtu.dk).

K. Martin is a Principal Engineer at Electric Power Group, Pasadena, California, USA (e-mail: kenm8421@yahoo.com). performance under frequency offsets and dynamic conditions, such as phase modulation [8], [9].

Recent publications propose methods that improve the accuracy under different dynamic or interference conditions An adaptive phasor and frequency tracking algorithm was proposed in [10] while [11] proposed a phase-locked-loop (PLL)-based technique in order to estimate dynamic phasors. Non-DFT dynamic signal models have been published in [12] [15] claiming improvements under dynamic conditions. The method proposed in [9] showed improved theoretical results under noise and harmonic conditions. New algorithms implemented in a prototype grid analyzer showed promising results for measurements carried out at distribution level [17]. However, most of the PMUs currently installed in today's power systems are of an older generation and are not fully compliant with the IEEE C37.118.1 standard, nor do they benefit from these more recent algorithm developments.

This paper presents testing of three commercial PMUs under three scenarios that occur in real power systems and are not covered by the current standard: high background noise, multiple harmonics, and current transformer (CT) saturation. The first test adds white noise to the AC signal. High noise can occur during switching and faults as well as during arcing, such as that created by a high resistance fault or failing equipment. In these situations, reasonably good PMU measurements would be expected (PMU measurements during faults are not expected to be accurate). In the second test, multiple harmonics are included with the AC signal, both at nominal and off-nominal system frequency. The standard only prescribes testing with a single harmonic at a time and only with the system frequency at nominal. This test can show if the present test in the standard covers harmonic interference that might be seen in real system operation. The third test is current measurement with saturated waveforms. CT saturation can occur with faulted or highly overloaded lines. DC flowing in the circuit can also lead to core saturation and measurement distortion [18]-[20]. Power converters used with the widely expanding renewable energy development can give rise to a DC component if the DC compensation sensor fails [21]. To obtain the best accuracy, PMUs are often connected to instrument CTs rather than protection CTs. This works well for most use, but during high overload conditions, these CTs may become saturated and provide misleading data. This test is intended to determine how significant the measurement impairments are and their characteristics.

These tests examine several areas of potential PMU vulnerability that have not been fully addressed. The 
synchrophasor standard, C37.118.1, provides a number of requirements to assure PMUs will perform adequately in field use. While there are many tests that could be used, the number of tests and test conditions is limited in order to make certification practical. The tests chosen for the standard are expected to be representative of PMU performance in real operational conditions. However, without testing to compare PMU performance as determined under the standard with conditions that might be encountered in a real power system, the standard effectiveness is not fully known. These tests provide a comparison in the cases of added harmonics and white noise as well as highly distorted input signals.

These tests both validate the tests in the standard and quantify the point at which the impairment limits the measurement accuracy. This information will be helpful in specifying new requirements and performance limits in future PMU standards.

Since these tests are performed on production PMUs, they show the overall performance limitations. It is difficult to assess the impacts of all the error contributions in a product that has not been implemented, so having actual results to refer to is essential to validate signal models. Standards are based on models and experience with development, so having quantified test results to validate the assumptions is essential for the standard development cycle.

These tests are on current generation PMUs but illustrate typical limitations in PMU measurement. All three PMUs performed similarly in all tests despite using different hardware and algorithms. PMU designers can use this observation to focus on aspects of their estimation methods that might reduce vulnerability to these impairments without reducing other measurement capability. In some cases, impaired measurements may have characteristics that are unique and can be flagged. The applications that use PMU data can use such flags to reject the measurement and improve reliability. These tests can indicate such characteristics.

The paper is organized as follows. Section II describes these test signals and their generation. The test system is described in section III. Section IV presents the results and analysis. The conclusions are in Section V.

\section{ANALYSIS OF INTERFERENCE CONDITIONS}

\section{A. Gaussian White Noise}

The C37.118.1 standard defines two tests that check the PMU filtering capabilities. These are the Out-of-Band interference and harmonic rejection tests. It does not include tests with white noise, though its influence on signal acquisition and measurement is a classic problem that has been studied [22]. Previous research has proposed algorithms that may improve measurement precision under noisy signals for PMUs [9]. The noise and harmonic content for distribution networks was investigated in [16] by collecting power grid signals; analysis showed that the SNR at the distribution level was around $60 \mathrm{~dB}$. This measurement is used as a guide for creating the tests and also for interpreting the results.

In this test, white noise is added to the fundamental frequency component of the voltage and current waveforms.
The noise level is gradually increased and the error evaluated. The SNR value is calculated based on the white noise only, since other contributions are very small. Analyzing the results of such an SNR sweep will give good understanding of the precision that PMUs are capable under noisy signals.

The digitized signals are created using the signal model,

$$
x(n)=A \cos \left(2 \pi\left(f_{0}+\Delta f\right) n T+\Phi\right)+w(n)
$$

where $A$ and $\Phi$ are the amplitude and initial phase angle of signal waveforms. The nominal system frequency is $f_{0}(50 \mathrm{~Hz}$ here), $\Delta \mathrm{f}$ is the deviation from nominal, and $w(\mathrm{n})$ is zero mean white Gaussian noise with the power spectral density (PSD) of $\rho^{2} \mathrm{~W} / \mathrm{Hz}[23]$.

The average power of signal $x$ without noise [24] is

$$
P_{x}=\lim _{N \rightarrow \infty} \frac{1}{2 N+1} \sum_{n=-N}^{N}|x(n)|^{2}
$$

The desired noise power is calculated from the signal power and desired signal-to-noise ratio as $\mathrm{P}_{\text {noise, } d \mathrm{~dB}}=\mathrm{P}_{\mathrm{x}, \mathrm{dB}}-\mathrm{SNR}_{\mathrm{dB}}$. The standard deviation of the white noise is

$$
\rho=\sqrt{10^{\left(P_{\text {noise }, d B} / 10\right)}}
$$

from which the term $w(\mathrm{n})$ is calculated.

The model described above reflects the effect of noise if the signal amplitude is kept constant. Hence both voltage and current amplitude is maintained at rated values for this test.

Testing at off-nominal frequencies can reveal issues with the processing algorithms of the PMU. For example, Fourier filters have very high rejection at the fundamental and the exact harmonic frequencies, but less rejection away from those points; consequently a fixed frequency Fourier filter may not give adequate rejection when the power system deviates from the nominal. This can be tested by changing the center frequency of the main signal. The standard specifies testing out-of-band rejection with an off-nominal frequency that is $\pm 10 \%$ of the Nyquist frequency for the given reporting rate. For a reporting rate of 50 samples per second, the Nyquist frequency is $25 \mathrm{~Hz}$ and thus $\Delta \mathrm{f}= \pm 2.5 \mathrm{~Hz}$. This deviation is used in these tests.

The test runs sequences of noise steps at each center frequency. In each sequence, the frequency is held constant and the noise level is increased by $5 \mathrm{~dB}$ at each step, starting at $-80 \mathrm{~dB}$ and ending at $-10 \mathrm{~dB}$. The noise level is held constant for 5 seconds during each step. Table I lists the frequencies used in this test together with the noise levels, and rated signal values.

Fig. 1 shows example plots of the signal with noise. Fig. 1a shows the envelope of the voltage signal where the overall amplitude increases with noise. The waveform detail with different SNRs is shown in Fig. 1b and Fig. 1c.

TABLE I

White Noise Test

\begin{tabular}{c|c|c|c}
\hline $\mathrm{V}[\mathrm{Vrms}]$ & \multicolumn{3}{|c}{110} \\
\hline $\mathrm{I}[\mathrm{Arms}]$ & \multicolumn{3}{|c}{5} \\
\hline $\mathrm{f}[\mathrm{Hz}]$ & 47.5 & 50 & 52.5 \\
\hline SNR $[\mathrm{dB}]$ & \multicolumn{2}{|c}{$10-80$ with $5 \mathrm{~dB}$ step increments } \\
\hline
\end{tabular}




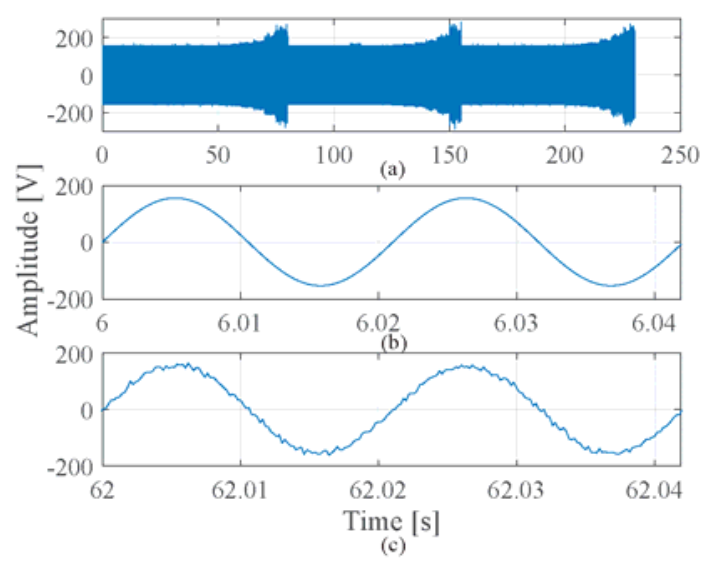

Fig. 1. Phase A Voltage Signal: (a) envelope of the signal showing the increased amplitude at the 3 test frequencies due to the injected noise; (b) Detailed view $\mathrm{f}_{0}=47.5 \mathrm{~Hz}, \mathrm{SNR}=80 \mathrm{~dB}$; (c) Detailed view $\mathrm{f}_{0}=47.5 \mathrm{~Hz}$, SNR $=25 \mathrm{~dB}$;

\section{B. Multiple Harmonics}

The C37.118.1 standard requires testing harmonic interference rejection from the second harmonic up to the fiftieth. In this test, harmonics are added to the fundamental one harmonic at a time with a level is $1 \%$ (of the fundamental) for $\mathrm{P}$ class and $10 \%$ for $\mathrm{M}$ class. By contrast power systems often contain multiple harmonics in both currents and voltages that may exceed $10 \%$ of the fundamental. As an example, one of the phenomena that causes multiple harmonics is the moment when a transformer is energized (transformer inrush) [25], [26]. As another example, multiple harmonics may be present in grids with renewable energy, such as wind farms with Type 3 and Type 4 wind turbines [27]. The research in [28] shows that Type 3 wind turbines inject predominantly low order harmonics $\left(5^{\text {th }}, 7^{\text {th }}, 11^{\text {th }}\right.$, and $\left.13^{\text {th }}\right)$ at a relatively high harmonic level. It is mentioned in [27] that fast control action of the wind turbine power converter can create low order harmonics. It is therefore relevant to know how commercially available PMUs will perform when they will be used for measuring signals with multiple harmonic contents. This test investigates whether using multiple harmonics rather than a single harmonic exposes additional PMU harmonic rejection vulnerability.

This multiple harmonic test uses harmonics (both number and relative amplitude) that have been observed during transformer inrush. As there is an infinite number of harmonic frequency and amplitude combinations, this choice provides a realistic combination to use for test. The current and voltage contents are typically different.

For example, during transformer inrush, the $2^{\text {nd }}$ harmonic current can reach values up to $63 \%$ of the fundamental, depending on the moment when the transformer is energized and the remnant flux within the core [23], [29]. The voltage harmonic amplitude can vary during the first cycles of the inrush with the 5 th and 6 th harmonics reaching values of $11 \%$ and $35 \%$ of the fundamental [30]. The inrush phenomenon comes with high amplitude in the fundamental as well, which can reach values five times the rated current [26]. However, this test does not inject such large currents into the PMUs because this would exceed the PMU input capability and render the measurement unusable, which would not fulfill the purpose of the test. Hence, the amplitude of both voltages and currents is kept constant at the rated value of $110 \mathrm{~V}$ and $5 \mathrm{~A}$.

This test includes single harmonics as specified in the standard and multiple harmonics between the $2^{\text {nd }}$ and $7^{\text {th }}$ as specified in Tables II and III. The values in these two tables are drawn from example situations presented in [29], [30].. The harmonics are tested in-phase, since there is no particular phase relationship reported. The test cases are run in sequence, each for 5 seconds. All cases are run both at nominal system frequency and off-nominal $(\Delta \mathrm{f}= \pm 2.5 \mathrm{~Hz})$ as in the noise tests. Testing at off-nominal frequency checks rejection, as described in the previous section.

TABLE II

Current Harmonic Content [29]

\begin{tabular}{|c|c|c|c|c|c|c|c|}
\hline \multirow{2}{*}{$\begin{array}{c}\text { Case } \\
\text { number }\end{array}$} & \multicolumn{6}{|c|}{ Harmonic number } & \multirow{8}{*}{ 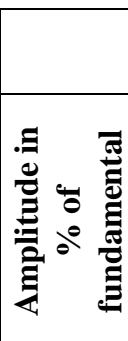 } \\
\hline & $2^{\text {nd }}$ & $3^{\text {rd }}$ & $4^{\text {th }}$ & $5^{\text {th }}$ & $6^{\text {th }}$ & $7^{\text {th }}$ & \\
\hline 1 & 31 & 13 & 2.5 & 2 & 1.8 & 1.2 & \\
\hline 2 & 37 & 16 & 3 & 2.4 & 2.2 & 1.4 & \\
\hline 3 & 44 & 19 & 3.6 & 2.8 & 2.6 & 1.6 & \\
\hline 4 & 50 & 21 & 4.1 & 3.2 & 2.9 & 1.9 & \\
\hline 5 & 56 & 24 & 4.6 & 3.7 & 3.3 & 2.1 & \\
\hline 6 & 63 & 27 & 5.1 & 4.1 & 3.7 & 2.4 & \\
\hline
\end{tabular}

TABLE III

Voltage Harmonic Content [30]

\begin{tabular}{|c|c|c|c|c|c|c|c|}
\hline \multirow{2}{*}{$\begin{array}{c}\text { Case } \\
\text { number }\end{array}$} & \multicolumn{6}{|c|}{ Harmonic number } & \multirow{8}{*}{ 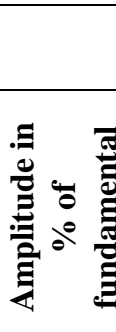 } \\
\hline & $2^{\text {nd }}$ & $3^{\text {rd }}$ & $4^{\text {th }}$ & $5^{\text {th }}$ & $6^{\text {th }}$ & $7^{\text {th }}$ & \\
\hline 1 & 0 & 1.5 & 1.5 & 7.5 & 35 & 0 & \\
\hline 2 & 0 & 3.8 & 7.6 & 7.7 & 3.8 & 0 & \\
\hline 3 & 0 & 3.5 & 6.15 & 6.15 & 6.15 & 0 & \\
\hline 4 & 0 & 3 & 4.6 & 8.5 & 4.6 & 0 & \\
\hline 5 & 0 & 0 & 2.3 & 11 & 2.3 & 0 & \\
\hline 6 & 0 & 3.8 & 7.4 & 11 & 35 & 0 & \\
\hline
\end{tabular}

Fig. 2a shows Phase A voltage amplitude during the entire test (all 6 cases).

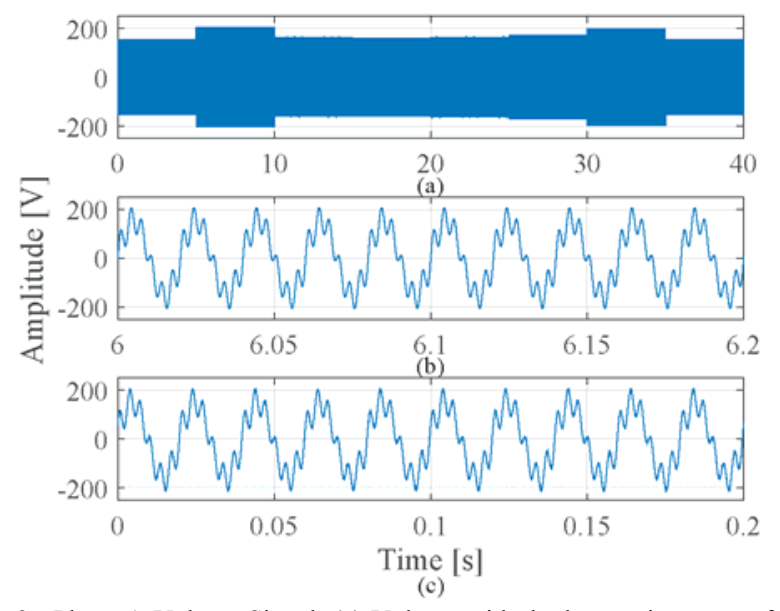

Fig. 2. Phase A Voltage Signal: (a) Voltage with the harmonic content from Table I; (b) Detailed view of the first case; (c) Oscilloscope measurement. 
The added amplitude due to harmonics can be seen. The harmonics in the signal are clearly visible in Fig. 2b, which is a section of plot (a) expanded to show the waveforms. In order to check if the created waveforms are the same as the generated ones, the actual analog test signal was captured with an oscilloscope for comparison. This capture is shown in Fig. $2 \mathrm{c}$.

\section{Current Transformer Saturation}

A CT connects the PMU to the high currents in the transmission system. High currents that exceed the normal operation capability, such as during a fault, can cause the core to saturate and produce a highly distorted signal [31]. This can lead to mis-operation of relays and other equipment that uses these signals, such as preventing tripping of equipment at the correct time that results in equipment damage [32].

The PMU standard specifies measurement accuracy at $1 \%$ Total Vector Error (TVE) for most tests. To take the full advantage of this accuracy, the CT should be in that accuracy range or better. According to IEEE C37.110-2007 Guide for CTs for protective Relaying [33], the expected accuracy of protection CTs at rated current is only $3 \%$. They will handle currents up to 20 times the rated current without losing more than $10 \%$ in accuracy, but this is not the focus of PMU measurements. More in the range of PMU operation, IEEE C57.13 standard for instrument transformers defines a metering category with accuracies between $0.3 \%$ and $1.2 \%$ for a current range of $10 \%-100 \%$ [34]. However, this standard does not give requirements regarding over-current capability and consequent saturation of these cores.

Generally, users will select metering cores for better accuracy in the normal range of operation even though it may be more subject to saturation. This test aims to determine how a saturated current waveform affects the PMU measurement.

A mathematical model of a CT was implemented in Matlab based on the theory published by the IEEE Power System Relaying Committee (PSRC). It is not the purpose of this paper to derive the full CT model so only the background is shown here; the full description can be found in "CT Saturation and Theory Calculator" [35].

The equivalent circuit of the CT model is shown in Fig. 3, where $i_{p}$ is the instantaneous primary current, $i_{2}$ represents the instantaneous real secondary current, $i_{e}$ is the instantaneous excitation current, and $v_{e}$ is the instantaneous excitation voltage. The number of CT turns is given by $N$, and $R s$ is the secondary winding resistance. The burden resistance is $R_{b}$, and inductance is $L_{b}$.

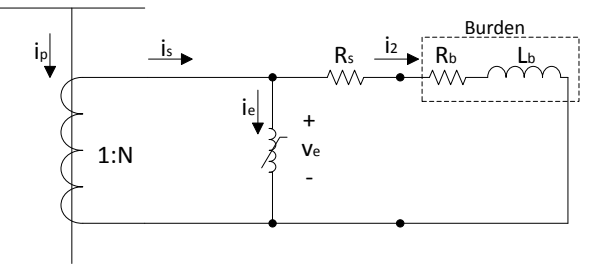

Fig. 3. CT model equivalent circuit

The excitation characteristic of a CT is illustrated by a plot of the secondary rms voltage versus the secondary excitation current, on log-log axes, as shown in Fig. 4. This curve is usually factory supplied. The model is based on two parameters from this characteristic: the saturation voltage $V_{S}$, chosen according to [33], at the point where the excitation current is $10 \mathrm{amps}$, and the inverse of the slope for the region above the knee-point voltage referred to as $S$. The normal operating region for the $\mathrm{CT}$ is below the knee voltage. As long as the CT operates in this region, the output will be accurate and linear.

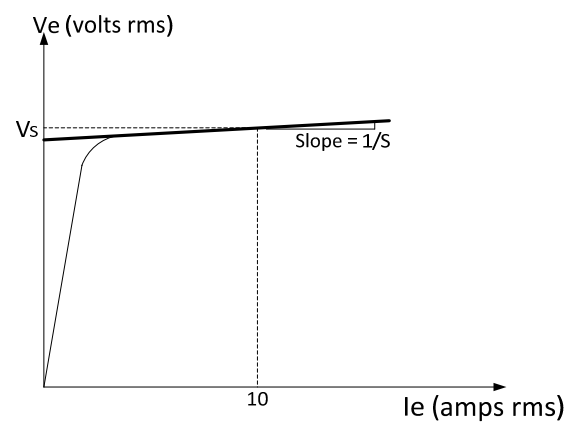

Fig. 4. Determination of the two required parameters from the CT excitation curve

The real secondary current $i_{2}$ is equal to the ideal current $i_{s}$ for the curve below the knee-point. This does not occur above the knee-point, where the CT core is saturating. The method uses the two extracted parameters, Vs and S, to calculate the real secondary current $i_{2}$, considering the saturation effect. This is achieved by calculating the excitation (error) current $i_{e}$ from Fig. 3. Because of the non-linearity of the system, instantaneous values of $i_{e}$ are computed using simple step increments. After each value for the excitation current is known, the real current is calculated as,

$$
i_{2}=i_{s}-i_{e}
$$

The full derivation of the method and equations can be found in [35].

The saturation level is quantified by the saturation factor $\mathrm{Ks}$, which is defined as [33],

$$
K_{S}=\frac{V_{e}}{V_{S}}=\frac{I_{F} *\left(Z_{B}+R_{S}\right)}{20 * I_{2} *\left(Z_{C}+R_{S}\right)}
$$

where $I_{F}$ is the secondary current during a fault, $I_{2}$ is the rated secondary current, $R_{S}$ is the winding resistance of the secondary side, $Z_{B}$ is the burden impedance including secondary devices and connection leads, and $Z_{C}$ is the standard CT burden according to class.

To test the PMUs, waveforms simulating CT saturation are created using the method summarized in this section. The test runs in sequences of saturation levels, quantified by Ks. In each sequence, $\mathrm{Ks}$ is increased in steps of 0.16 starting at $\mathrm{Ks}=0.5$ and ending at $\mathrm{Ks}=2$. The waveforms start to saturate when $\mathrm{Ks}>1$.

The current level injected in the PMUs is increased along with Ks. This helps simulate a real event where the current supplied by a CT would exceed the rated value. The PMUs 
used have been tested according to the steady-state IEEE requirements in [36] and their accuracy is shown to be within standards limits for currents up to $200 \%$ the rated value.

In Fig. 5a and Fig. 5b, the red line overlaps the blue, meaning that the secondary current is identical to the ideal one. In Fig. $5 b$, the saturation factor $\mathrm{Ks}=1$ meaning the $\mathrm{CT}$ is at its limit and will start to saturate. Fig. 5c shows the current waveform when $\mathrm{Ks}=2$. The current represented by the red line is the one injected in the PMUs and the measurements are compared to the current represented by the blue line which is the ideal value.

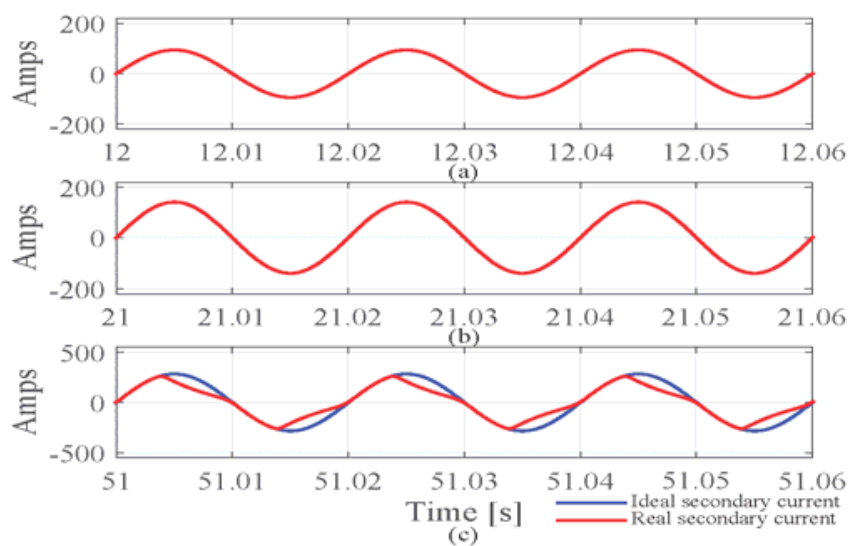

Fig. 5. Ideal vs real secondary current when: (a) $\mathrm{K}_{\mathrm{S}}=0.65$; (b) $\mathrm{K}_{\mathrm{S}}=1$; (c) $\mathrm{K}_{\mathrm{S}}=2$ (saturated core)

\section{Test SETUP}

The lab test setup used is similar to setups used and published before [4]-[7], [37]-[41]. More advanced setups are described in [42]-[44].

The setup consists of a real time playback device that supplies analog voltage and current signals at a level and format suitable for PMU inputs (110 V-nominal voltage and 5A nominal current) using recorded COMTRADE files. The output of the test set uses 16-bit D/A converters that are GPS synchronized, offering precise test start and signal time alignment. As such, the measurements can be aligned with the theoretical values at the evaluation stage.

Some of the PMUs under test come with their own GPS receivers built-in while others require a separate GPS receiverclock in order to obtain UTC synchronization. The receiver used in the test is rated with an accuracy of $\pm 1 \mu \mathrm{s}$.

A number of possible error sources associated with the test setup consist of the playback device amplifier, GPS receiver and playback startup delay [5]. A calibration of the test set was carried out in order to verify the deviation in voltage amplitude from the theoretical value. The output of the test set was read with four high-accuracy voltmeters and the average of the four measurements was considered as the true value.

A correction factor was defined as the deviation of the average measured voltage from the theoretical value. The correction was calculated to be approximately $0.06 \%$.

The startup delay time was checked with an oscilloscope that was triggered on the 1 PPS signal obtained from the GPS receiver clock. All three phases were checked simultaneously, and a time lag of $142 \mu$ s was found. This translates into a phase error of 2.556 degrees and it was consistent through multiple tests.

It is obvious that these errors would cause high TVE and need to be compensated. This is achieved by introducing correction factors in the theoretical signals defined in (6) and achieving the compensated signal defined in (7),

$$
\begin{gathered}
\text { Sig }=X_{m} * \cos (2 \pi f t+\theta) \\
\text { Sig }=\left[X_{m} * a m p_{c o r r}\right] * \cos \left(2 \pi f t-\theta_{c o r r}+\theta\right)
\end{gathered}
$$

where $a m p_{c o r r}$ is the amplitude correction factor, and $\theta_{\text {corr }}$ is the phase angle correction factor.

In [1], it is recommended that the test uncertainty is maintained less than one-fourth of the accuracy requirement, and with the compensation, the test setup used here is within this requirement.

Fig. 6 shows a diagram of the complete test setup. The PC runs all the necessary software to build the test signals and analyze the results. The three PMUs under test are connected simultaneously to the signal generator and their measurements are recorded by the Phasor Data Concentrator (PDC). The blue arrows show the voltage inputs connected in parallel and the red arrows represent the current inputs connected in series.

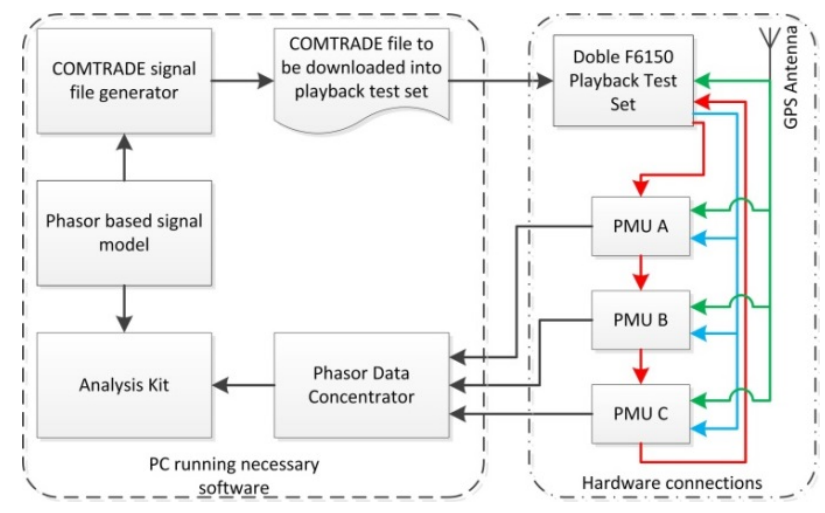

Fig. 6. Test setup diagram

\section{TEST RESUlts}

This section presents the analysis of the PMU measurements under the three aforementioned scenarios. The testing parameters are shown in Table IV. The devices are set to the M-class which includes better filtering for better performance, particularly under interference conditions. Information about other PMU parameters, such as signal sampling rate, and $n$. of observed cycles for each phasor measurement, is not provided by the vendors.

The performance is analyzed according to IEEE C37.118.1a by calculating the TVE, Frequency Error (FE), ROCOF Error (RFE). Error Calculation for Magnitude Error (ME), and Phase Error (PE) is defined as [3],

$$
\operatorname{ME}(\%)=\frac{\sqrt{\widehat{X}_{\mathrm{r}}(\mathrm{n})^{2}+\widehat{\mathrm{X}}_{\mathrm{i}}(\mathrm{n})^{2}}-\sqrt{\mathrm{X}_{\mathrm{r}}(\mathrm{n})^{2}+\mathrm{X}_{\mathrm{i}}(\mathrm{n})^{2}}}{\sqrt{\mathrm{X}_{\mathrm{r}}(\mathrm{n})^{2}+\mathrm{X}_{\mathrm{i}}(\mathrm{n})^{2}}}
$$




$$
\operatorname{PE}(\operatorname{deg})=\operatorname{atan}\left(\widehat{\mathrm{X}}_{\mathrm{r}}(n), \widehat{\mathrm{X}}_{\mathrm{i}}(n)\right)-\operatorname{atan}\left(\mathrm{X}_{\mathrm{r}}(n), \mathrm{X}_{\mathrm{i}}(\mathrm{n})\right)
$$

Where $\widehat{\mathrm{X}}_{\mathrm{r}}(\mathrm{n})$, and $\widehat{\mathrm{X}}_{\mathrm{i}}(\mathrm{n})$ are sequences of the real and imaginary parts of phasor estimates from PMUs under test at time $n$, and $X_{r}(n)$, and $X_{i}(n)$ are sequences of theoretical phasor values of the input signal at the same time $n$.

Table IV

Testing Parameters

\begin{tabular}{|c|c|c|c|c|}
\hline Test type & $\begin{array}{l}\text { Signal } \\
\text { frequency } \\
{[\mathrm{Hz}]}\end{array}$ & $\begin{array}{l}\text { PMU } \\
\text { Reporting } \\
\text { Rate } \\
\text { [samples/sec] }\end{array}$ & $\begin{array}{l}\text { Observation } \\
\text { interval }\end{array}$ & $\begin{array}{l}\text { Processed } \\
\text { samples for } \\
\text { each } \\
\text { interval }\end{array}$ \\
\hline $\begin{array}{l}\text { White } \\
\text { Noise }\end{array}$ & $47.5 / 50 / 52.5$ & \multirow{4}{*}{50} & \multirow{4}{*}{$\begin{array}{c}\text { All test } \\
\text { segments are } \\
5 \text { seconds } \\
\text { long }\end{array}$} & \multirow{4}{*}{$\begin{array}{l}250 \text { sample } \\
\text { points }\end{array}$} \\
\hline $\begin{array}{c}\text { Multiple } \\
\text { Harmonics }\end{array}$ & $47.5 / 50 / 52.5$ & & & \\
\hline $\begin{array}{c}\text { Single } \\
\text { Harmonic }\end{array}$ & $47.5 / 50 / 52.5$ & & & \\
\hline $\begin{array}{c}\mathrm{CT} \\
\text { Saturation } \\
\end{array}$ & 50 & & & \\
\hline
\end{tabular}

All test segments are 5 seconds long. The maximum error for each segment is determined and used for the error plot.

\section{A. Gaussian White Noise Test}

The PMU performance under white noise conditions is presented in this subsection. The test is similar with the Outof-Band test defined in IEEE C37.118.1, so the 1.3\% TVE, $0.01 \mathrm{~Hz} \mathrm{FE}$, and $0.1 \% \mathrm{RFE}$ limits are used to evaluate the measurements. The RFE limit in the standard is suspended for evaluations, but the old limit is used here as a reference for comparisons. The figures show how the accuracy of the measurement for phasors, frequency and rate of change of frequency is affected by different noise levels.

The TVE of the voltages and currents in Fig. 7 show that all PMUs are within the limits for high and medium signal-tonoise ratios. For SNRs around $30 \mathrm{~dB}$ and lower, the accuracy exceeds the $1.3 \%$ limit and continues to drop significantly afterwards.
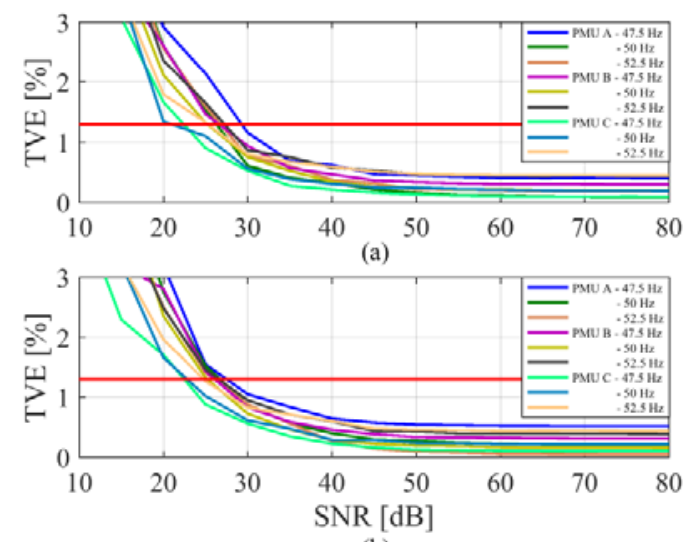

(b)

Fig. 7. Phase A; TVE limit $=1.3 \%$; (a) Voltage; (b) Current

In Fig. 8 and Fig. 9, it can be seen that the PMUs are more sensitive to noise when it comes to frequency estimation. In Fig. 8b, PMU A is more affected by noise than PMUs B and
C, which shows that the PMUs adopt very different processing algorithms. Its frequency error is exceeding the $0.01 \mathrm{~Hz}$ limit at around $45 \mathrm{~dB}$ where the other devices have an accuracy of 5 $\mathrm{mHz}$. A few possible reasons are presented in [45], such as the leakage effect for SNR higher than $35 \mathrm{~dB}$ and frequency deviation greater than $1 \mathrm{~Hz}$.
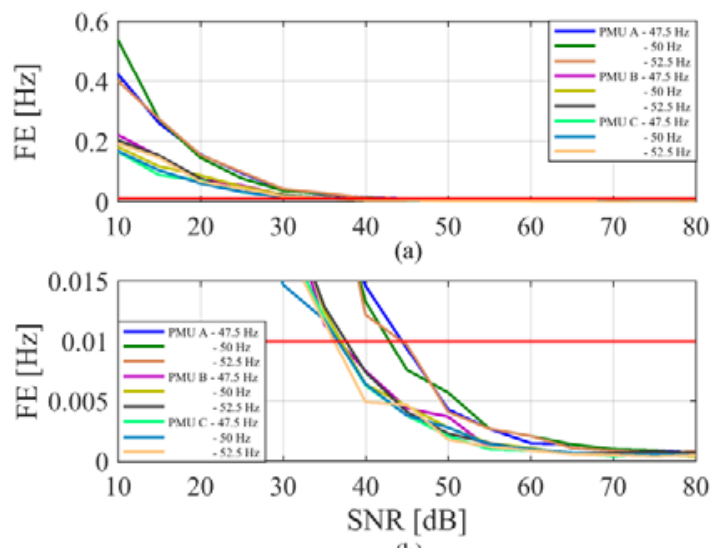

(b)

Fig. 8. Frequency Error: (a) Maximum error; (b) detail of (a) showing the error limit
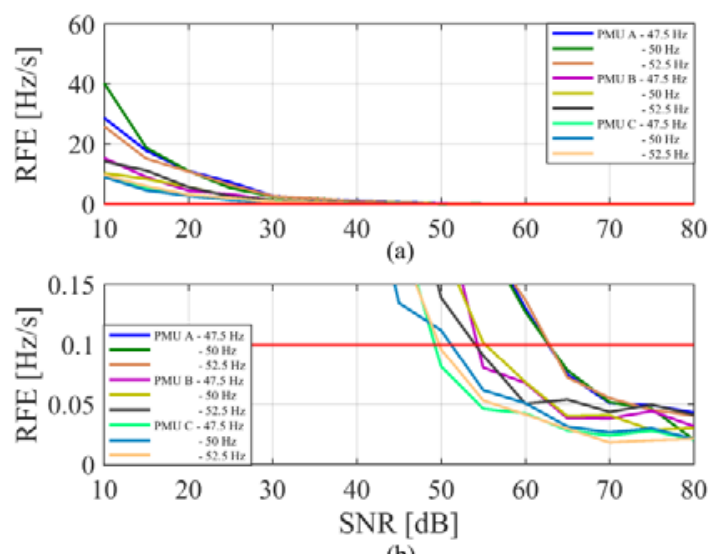

(b)

Fig. 9. ROCOF Error: (a) Maximum error;

(b) detail of (a) showing the error limit

The ROCOF is even more affected by noise. PMU A is the first to exceed the limit at about $63 \mathrm{~dB}$ while the others still meet the requirement at $56 \mathrm{~dB}$. Since the frequency from PMU $\mathrm{A}$ is more affected by noise than the others, it makes sense that its ROCOF measurement will be also.

Based on these results, it is clear that the frequency and ROCOF measurements are much more affected by noise, as expected since these are the first and second derivatives of the phase angle. It can also be seen that the knee of the curve, where noise causes the error curves to deviate from the noise floor, is around $40 \mathrm{~dB}$ for phasors (TVE), $55 \mathrm{~dB}$ for frequency (FE), and $65 \mathrm{~dB}$ for ROCOF (RFE).

As long as the noise in the test signals remains above 65 dB SNR, the outcome of the tests specified by the standard will be unaffected. If signals with higher noise power are to be measured by PMUs, some compensation or adjustments should be made to the devices in order to reduce the error 
levels. Adjustments such as a longer observation window (number of cycles used by the PMU for estimation), an increased sampling rate, and a larger effective number of bits of the A/D sampling could improve the accuracy under noise conditions. Reference [46] describes details on how these adjustments affect the accuracy of the PMU, and advantages and possible disadvantages of such adjustments. A number of guidelines are also provided in [46] to help PMU designers make a balanced choice of these parameters.

\section{B. Multiple Harmonics Test}

The multiple harmonics test is an extension of what the standard requires. In this case, multiple harmonics are injected simultaneously and the accuracy of the PMUs is analyzed. The three phase voltages and currents have different harmonic components. Since the frequency of the power system is not always at its nominal value, the harmonic rejection capabilities of the PMUs are also tested at off-nominal frequencies. Fig. 10 and Fig. 11 show the TVE of the voltages and currents with multiple harmonics included, and signal frequencies of $50 \mathrm{~Hz}$ and $52.5 \mathrm{~Hz}$, respectively. It is clear that, in both cases, the accuracy of the tested PMUs is well within the limits defined in the IEEE C37.118.1 standard.
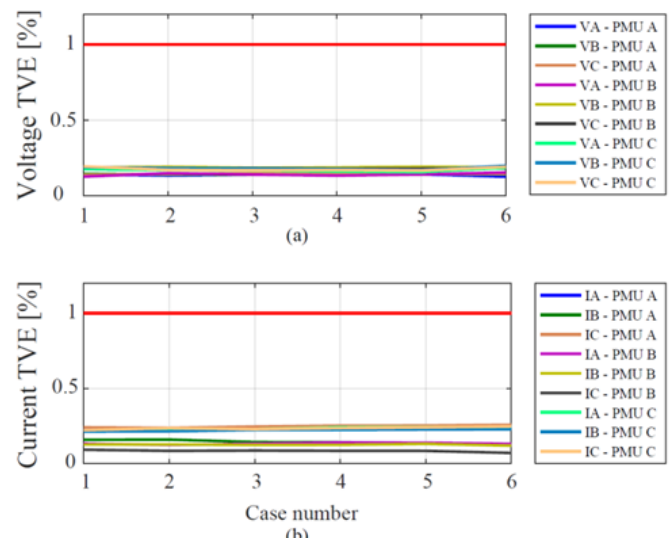

Fig. 10. Multiple harmonic rejection: (a) Voltage analysis; (b) Current analysis; Signals frequency $\mathrm{f}=50 \mathrm{~Hz}$

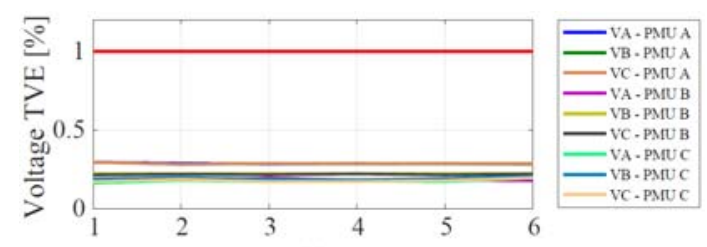

(a)

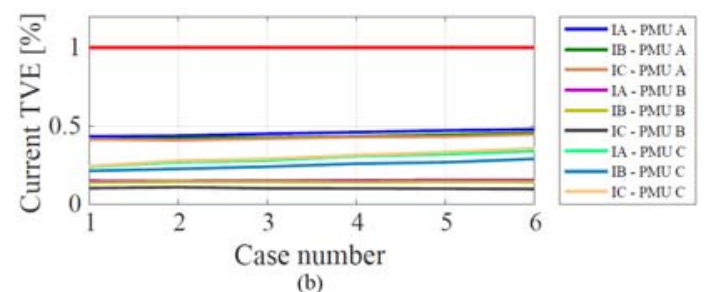

Fig. 11. Multiple harmonic rejection: (a) Voltage analysis; (b) Current analysis; Signals frequency $\mathrm{f}=52.5 \mathrm{~Hz}$

The results of this test demonstrate that these PMUs provide sufficient filtering to suppress the multiple harmonics interference in these cases. The frequency measurement and ROCOF estimation are shown in Fig. 12 and Fig. 13. They are accurate for all PMUs in both nominal and off-nominal cases.
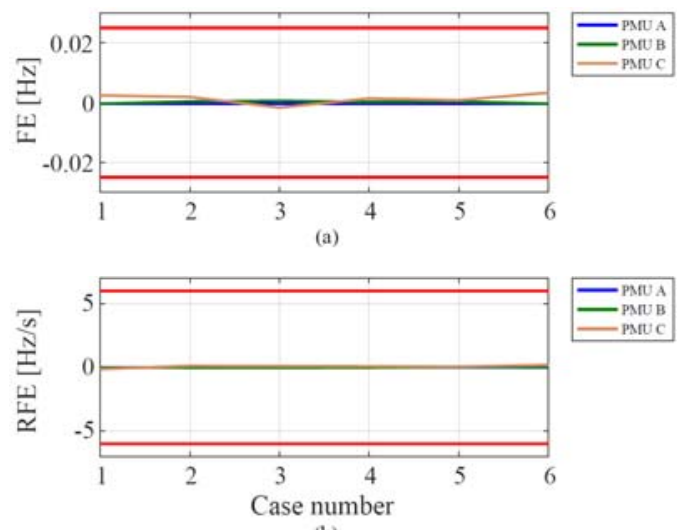

Fig. 12. Multiple harmonic rejection: (a) Frequency Error; (b) ROCOF Error; Signals frequency $\mathrm{f}=50 \mathrm{~Hz}$
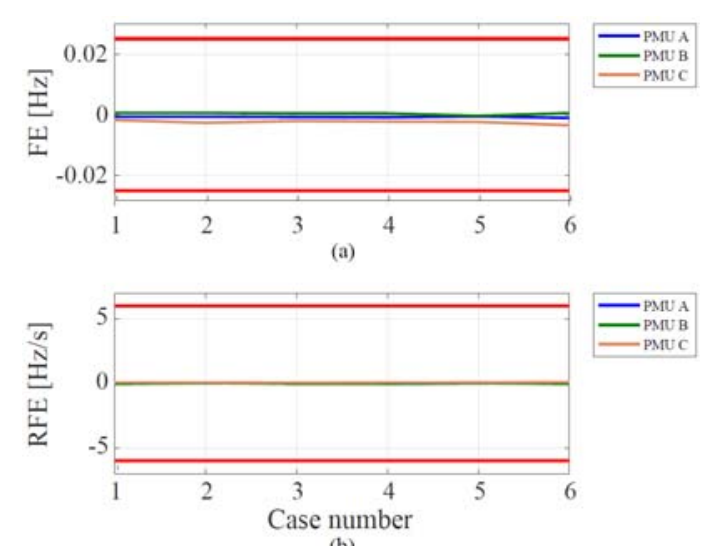

(b)

Fig. 13. Multiple harmonic rejection: (a) Frequency Error; (b) ROCOF Error; Signals frequency $\mathrm{f}=52.5 \mathrm{~Hz}$

In addition, the devices are also tested for single harmonic interference at nominal and off-nominal frequencies. The injected signals contain one harmonic at a time, from $2^{\text {nd }}$ to $50^{\text {th }}$. The amplitude of the harmonics is $10 \%$ of the fundamental. Fig. 14 to Fig. 17 show that the tested PMUs successfully filter the single harmonics at both nominal and off-nominal frequencies.
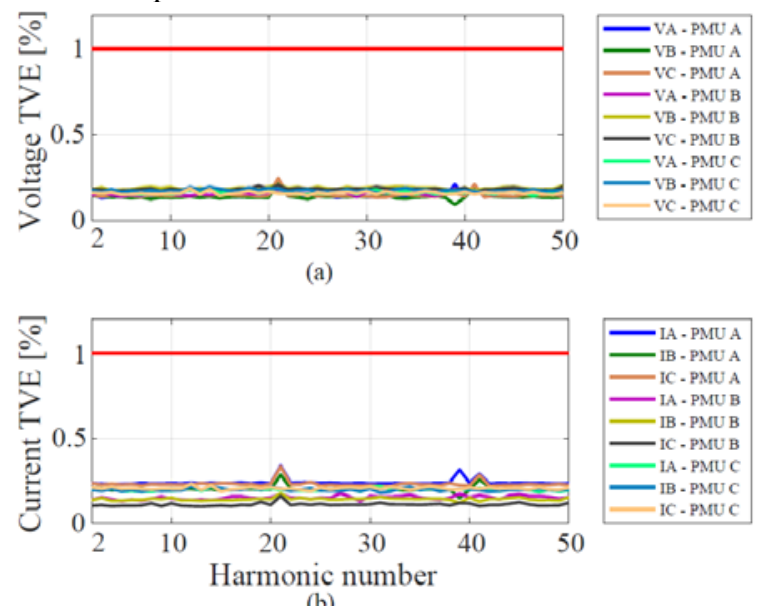

(b)

Fig. 14. Single harmonic rejection: signal frequency $\mathrm{f}=50 \mathrm{~Hz}$; (a) Voltage analysis; (b) Current analysis 


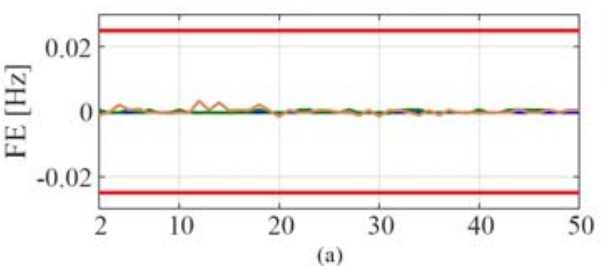

(a)

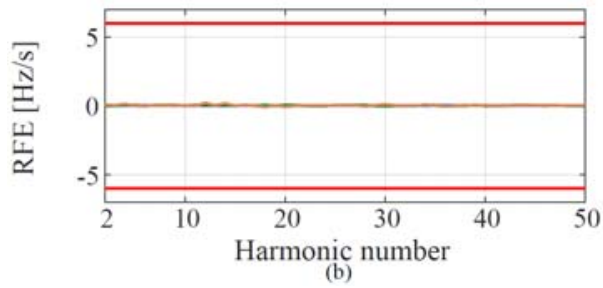

\section{PMUA} -

Fig. 15. Single harmonic rejection: signal frequency $\mathrm{f}=50 \mathrm{~Hz}$; (a) Frequency Error; (b) ROCOF Error
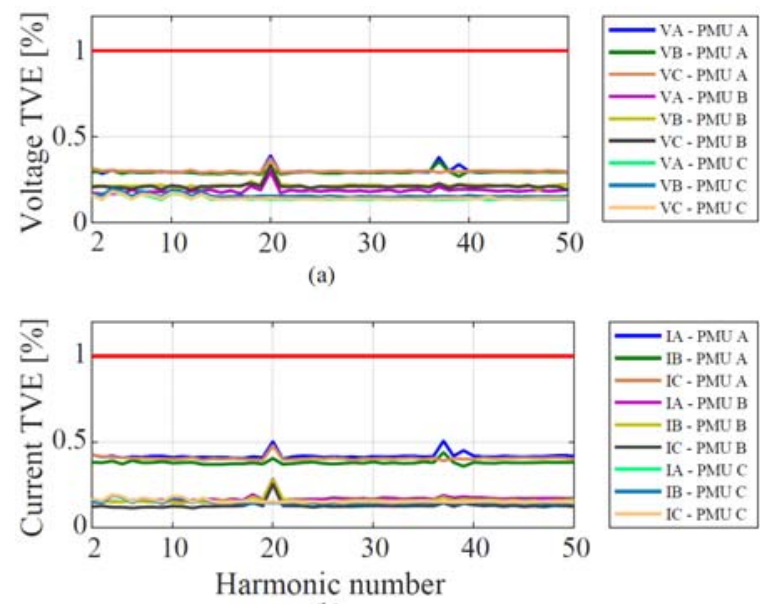

Fig. 16. Single harmonic rejection: signal frequency $\mathrm{f}=52.5 \mathrm{~Hz}$; (a) Voltage analysis; (b) Current analysis
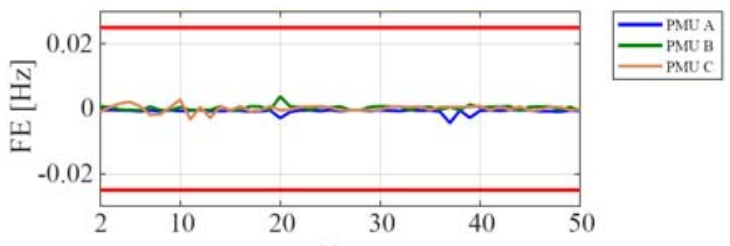

(a)
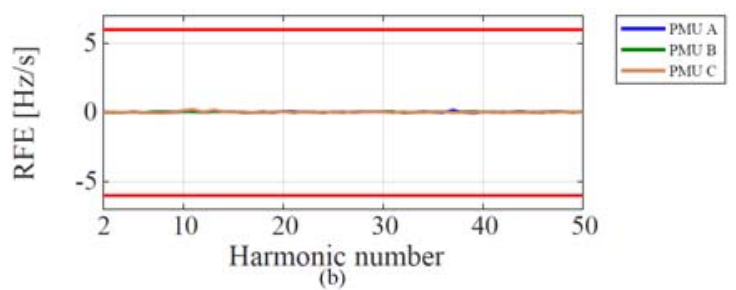

Fig. 17. Single harmonic rejection: signal frequency $\mathrm{f}=52.5 \mathrm{~Hz}$

(a) Frequency Error; (b) ROCOF Error

It can be concluded that these PMUs have sufficient filtering to suppress harmonic interference for both single and multiple harmonic contents, even when the base frequency is off-nominal.

\section{Current Transformer Saturation Test}

This test is similar to the Amplitude Scan test defined in IEEE C37.118.1, so the 1\% TVE limit is used for comparing the accuracy of the PMUs.

Fig. 18 shows the accuracy of the current measurement versus the saturation factor. It can be seen that all devices are within the limit as long as there is no saturation, $\mathrm{K}_{\mathrm{S}} \leq 1$. The performance decreases rapidly once saturation occurs.

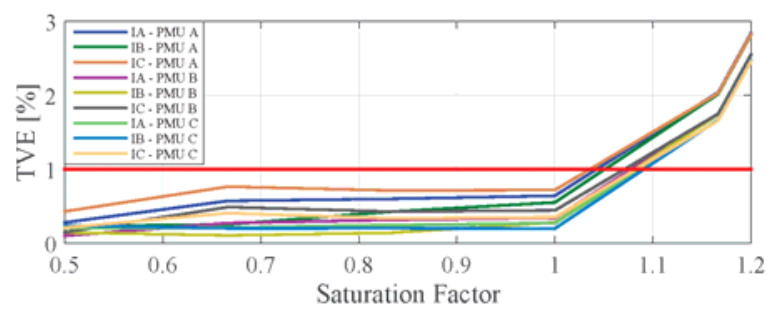

Fig. 18. CT saturation test: Current Total Vector Error
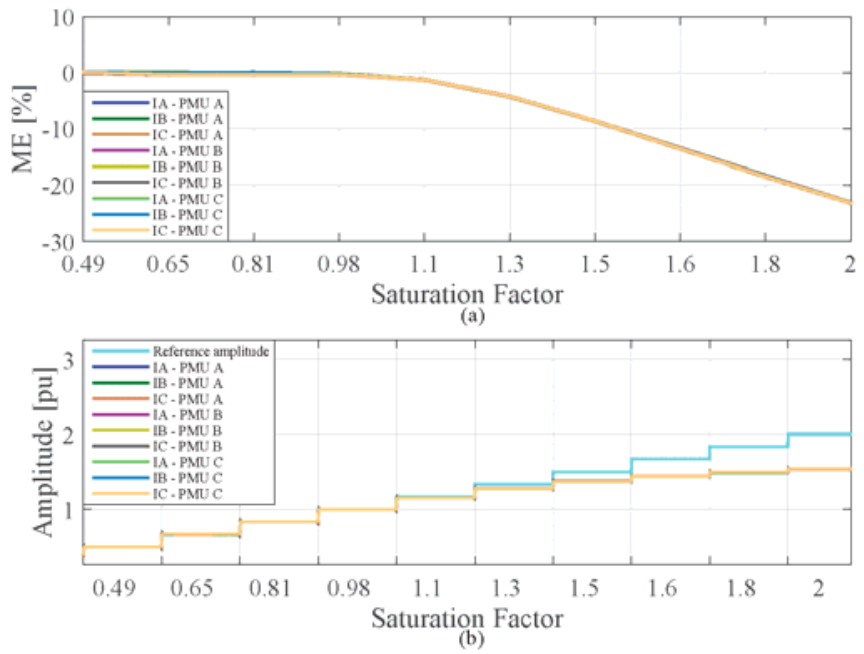

Fig. 19. CT saturation test: (a) Current Magnitude Error; (b) Current amplitude
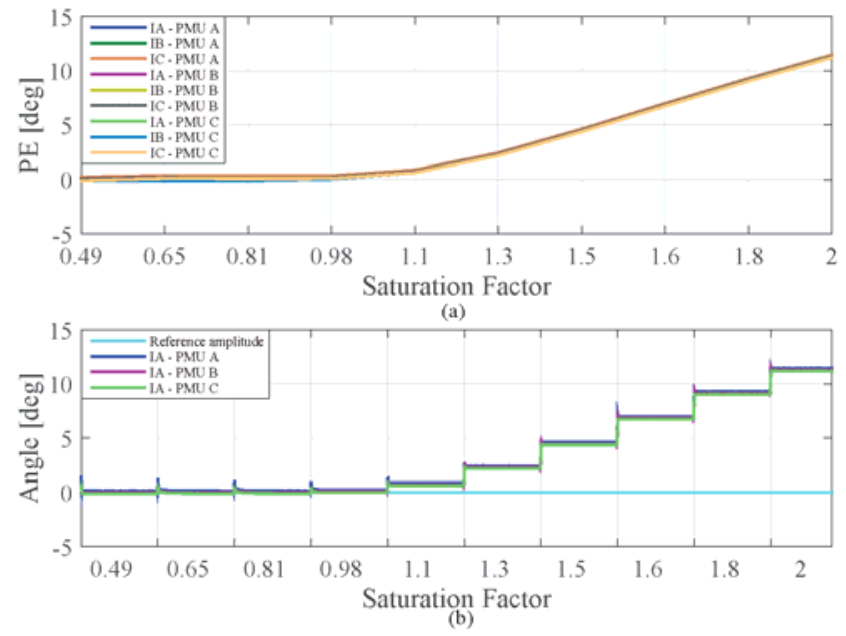

Fig. 20. CT saturation test: (a) Current Phase-A Error; (b) Current Phase-A angle

Fig. 19 and Fig. 20 give an insight to the amplitude and angle measurements. It is shown that the measured amplitude 
tends to flatten out as the saturation increases. In contrast, the measured angle shows an increase while it should stay constant. In Fig. 20, the angle of phase A is shown together with the reference value. All three phases of all PMUs are plotted in the figures, except for Fig. 20b, where only phase A of all PMUs is shown. Phases B and $\mathrm{C}$ follow the same trend as phase $\mathrm{A}$, and this is visible in Fig 20a where the phase error for all angles increases.

The Frequency Error and ROCOF Error are not evaluated, because these PMUs use voltage measurements in order to estimate these quantities. For this test, the voltages were kept at the nominal value and the Frequency and ROCOF are not affected.

The results show that CT saturation degrades the accuracy of the PMU measurements. Correct choice and installation of CTs helps prevent saturation. However, it can still occur during faults, or if a DC current flows in the circuit and incorrect PMU measurements can reach the control algorithms. Following the specific trend where amplitude flattens and angle increases, the event could be detected from the PMU raw measurements and then indicated by a flag.

\section{CONCLUSION}

This paper has looked into the PMU performance under three plausible power system interference conditions. Three production PMUs were used in this test. They were all configured for M-class since it provides the greatest interference filtering and is expected to make the most precise measurements.

The testing uses white noise to test resistance to broad-band interference. It was shown that these PMUs successfully reject noise down to around $40 \mathrm{~dB}$ SNR before the phasor measurements fail to meet the specifications. Frequency and ROCOF measurements fail below about $55 \mathrm{~dB}$ and $65 \mathrm{~dB}$, respectively. Better filtering, or improved processing techniques will be required for acceptable results, particularly for frequency and ROCOF measurements, if PMUs are used in high noise environments.

Multiple harmonics tests show that these are rejected by the PMU filtering just the same as single harmonics both in nominal and off-nominal frequency cases. Phasors, frequency and ROCOF are accurately estimated and reported in all cases by the tested PMUs. This result indicates that the single harmonic testing at nominal frequency is adequate for verifying harmonic rejection.

PMU measurement failure starts at a low level of CT core saturation $(\mathrm{Ks}=1.2)$. This could lead to control or protection error if not detected. There seems to be a pattern in this case as amplitude flattens and angle increases but is not distinct enough to clearly identify such an event from the data itself. Since the phasor only includes the sinusoidal parameters, waveform distortion is not reported. It can be better detected from the raw measurement in the PMU and then indicated through an error flag that is transmitted with the data.

The emphasis was on PMU performance under impairments which could be seen in operating power systems, and the comparison with results that would be seen from C37.118.1 testing. The tests showed that noise degrades measurement at fairly high SNRs, especially for frequency and ROCOF estimations. While not surprising, this should encourage PMU designers to develop and implement methods more resistant to noise. The fact that single or multiple harmonics at nominal or off-nominal frequencies did not significantly degrade measurements indicates that current testing methods in the standard are adequate. Finally, distorted waveforms will certainly degrade the measurement, but possibly this is at a higher level than expected.

The results can also be used for PMU and phasor application development, particularly regarding signatures related to certain impairments. For example, an application designer could detect high noise through a tracking filter and use that to relax trigger points, making the application more robust. A small signature was noted with CT saturation distortion (flattening amplitude with decreasing phase angle). This is not distinct enough to flag the event, particularly as saturation will usually occur very fast. Finally, harmonic rejection proved to be good, so it is not likely to be an area that needs additional development.

\section{REFERENCES}

[1] IEEE Standard for Synchrophasor Measurements for Power Systems IEEE Std C37.118.1 $1^{\mathrm{TM}}-2011$.

[2] Amendment 1: Modification of Selected Performance Requirements IEEE Std C37.118.1 $\mathrm{a}^{\mathrm{TM}}-2014$ (Amendment to IEEE Std C37.118.1 ${ }^{\mathrm{TM}}$ 2011).

[3] "IEEE Synchrophasor Measurement Test Suite Specification," IEEE-SA Conformity Assessment Program, December 2014.

[4] R. Ghiga, Q. Wu, K. Martin, W. Ziad, L. Cheng and A. H. Nielsen, "Dynamic PMU Compliance Test under C37.118.1a ${ }^{\mathrm{TM}}-2014$, , in Proc. IEEE PES General Meeting, Denver, CO, 2015, pp. 1-5.

[5] D.R. Gurusinghe, A.D. Rajapakse, and K. Narendra, "Testing and Enhancement of Dynamic Performance of a Phasor Measurement Unit," IEEE Trans. Power Del., vol. 29, no. 4, August 2014.

[6] K. Narendra, D. R. Gurusinghe, and A.D. Rajapakse, "Dynamic Performance Evaluation and Testing of Phasor Measurement Unit (PMU) as per IEEE C37.118.1 Standard," Presented at the Doble Client Committee Meetings Int. Protect. Testing Users Group, Chicago, IL, USA.

[7] D.R. Gurusinghe, A.D. Rajapakse, and K. Narendra, "Evaluation of Steady-State and Dynamic Performance of a Synchronized Phasor Measurement Unit," in Proc. IEEE Elect. Power Energy Conf., London, ON, Canada, 2012, pp. 57-62.

[8] A. Phadke and B. Kasztenny, "Synchronized phasor and frequency measurement under transient conditions," IEEE Trans. Power Del., vol. 24, no. 1, pp. 89-95, Jan. 2009.

[9] D. Macii, D. Petri, and A. Zorat, "Accuracy Analysis and Enhancement of DFT-Based Synchrophasor Estimators in Off-Nominal Conditions," IEEE Trans. Instrum. Meas., vol. 61, no. 10, pp. 2653-2664, Oct. 2012.

[10] I. Kamwa, A. K. Pradhan, and G. Joos, "Adaptive phasor and frequency tracking schemes for wide-area protection and control," IEEE Trans. Power Del., vol. 26, no. 2, pp. 744-753, Apr. 2011.

[11] M. Karimi-Ghartemani, B.T. Ooi, and A. Bakhshai, "Application of enhanced phase-looked loop system to the computation of synchrophasor," IEEE Trans. Power Del., vol. 26, no. 1, pp. 22-32, Jan. 2011.

[12] J. A. de la O Serna, "Dynamic phasor estimates for power system oscillations," IEEE Trans. Instrum. Meas., vol. 56, no. 5, pp. 16481657, Oct. 2007.

[13] J. A. de la O Serna, "Dynamic phasor estimates for power system oscillations and transient detection," in Proc. IEEE PES General Meeting, Montreal, QC, Canada, 2006, pp. 1-7.

[14] M. A. Platas-Garza and J. A. de la O Serna, "Dynamic phasor and frequency estimates through maximally flat differentiators," IEEE Trans. Instrum. Meas., vol. 59, no. 7, pp. 1803-1811, Jul. 2010. 
[15] L. Zhan and Y. Liu, "Improved WLS-TF algorithm for dynamic synchronized angle and frequency estimation," in Proc. IEEE PES General Meeting, National Harbor, MD, 2014, pp. 1-5.

[16] L. Zhan, Y. Liu, J. Culliss, J. Zhao, and Yilu Liu, "Dynamic SinglePhase Synchronized Phase and Frequency Estimation at the Distribution Level," IEEE Trans. Smart Grid, vol. 6, no. 4, pp. 2013-2022, July 2015.

[17] L. Zhan, J. Zhao, J. Culliss, Y Liu, Yilu Liu, S. G., "Universal Grid Analyzer Design and Development," in Proc. IEEE PES General Meeting, Denver, CO, USA, July 2015, pp. 1-5.

[18] J. G. Kappenman, V. D. Albertson, and N. Mohan, "Current Transformer and Relay Performance in the Presence of Geomagnetically-Induced Currents," IEEE Trans. Power App. Syst., vol. PAS-100, no. 3, pp. 1078-1088, Mar. 1981.

[19] F. Bachinger, A. Hackl, P. Hamberger, Leikermoser, G. A. Leber, H. Passath, and M. Stoessl, "Direct current in transformers: Effects and compensation," in CIGRE Session, SC A2, Paris, Aug. 2012, pp. 1-5.

[20] K. Draxler and R. Styblíková, "Effect of Magnetization on Instrument Transformers Errors,” J. Electr. Eng., vol. 61, no. 7/s, pp. 50-53, 2010.

[21] G. Buticchi, E. Lorenzani, and G. Franceschini, "A DC Offset Current Compensation Strategy in Transformerless Grid-Connected Power Converters," IEEE Trans. Power Del., vol. 26, no. 4, pp. 2743-2751, Oct. 2011.

[22] C. Offelli and D. Petri, "Weighting effect on the discrete time Fourier transform of noisy signals," IEEE Trans. Instrum. Meas., vol. 40, no. 6, pp. 972-981, Dec. 1991.

[23] C. R. Mason, The Art and Science of Protective Relaying. 2nd ed., John Wiley, New York, 1986.

[24] J. G. Proakis and D. G. Manolakis, Digital Signal Processing, Principles, Algorithms, and Applications. 3rd ed., Prentice-Hall Inc., New Jersey, 1996.

[25] L. F. Blume, G. Camilli, S.B. Farnham, and H.A. Peterson, "Transformer Magnetizing Inrush Currents and Influence on System Operation," AIEE Trans., vol. 63, no. 6, pp. 366-375, Jun. 1944.

[26] H. S. Bronzeado, P.B. Brogan, R. Yacamini, "Harmonic Analysis of Transient Currents During Sympathetic Interaction," IEEE Trans. Power Syst. , vol. 11, no. 4, pp. 2081-2056, Nov. 1996.

[27] B. Badrzadeh, M. Gupta, N. Singh, A. Petersson, L. Max, and M Hogdahl, "Power system harmonic analysis in wind power plants-Part I: Study methodology and techniques," in Proc. IEEE Ind. Appl. Soc. Annual Meeting, Las Vegas, NV., Oct. 2012, pp.1-11.

[28] S. Liang, Q. Hu, and W. Lee, "A survey of harmonic emissions of a commercial operated wind farm," in Proc. IEEE Industrial and Commercial Power Systems Technical Conf., Tallahassee, FL, USA, May 2010, pp. 1-8.

[29] Ahmed M. A. Alomar, Bakr E. M. Shamseldin, "Alternative Approaches for Distinguishing between Faults and Inrush Current in Power Transformers," Scientific Research, Energy and Power Engineering, pp. 143-160, Jul 2014.

[30] Ryan A. Turner, Kenneth S. Smith, "Transformer Inrush Currents. Harmonic Analysis in Interconnected Power Systems," IEEE Ind. Appl. Mag., vol. 16, no. 5, pp. 14-19, Sept.-Oct. 2010.

[31] E. C. Segatto and D. V. Coury, "A power transformer protection with recurrent ANN saturation correction," in PrOc. IEEE PES General Meeting, vol.2, 12-16 June 2005, pp. 1341-1346.

[32] I. M. El-Amin and N. H. Al-Abbas, "Saturation of Current Transformers and its Impact on Digital Overcurrent Relays," in Proc. IEEE Transmission \& Distribution Conference and Exposition: Latin America, Aug. 2006, pp. 1-6.

[33] IEEE Guide for the Application of Current Transformers Used for Protective Relaying Purposes, IEEE Std C37.110 ${ }^{\mathrm{TM}}-2007$.

[34] IEEE Standard Requirements for Instrument Transformers, IEEE Std $\mathrm{C} 57.13^{\mathrm{TM}}-2008$

[35] G. Swift, "CT Saturation Theory and Calculator," IEEE Power Syst. Relaying and Control Committee, pp 1-9, June 2001.

[36] R. Ghiga, Q. Wu, K. Martin, W. El-Khatib, L. Chen and A. H. Nielsen, "Steady-State PMU Compliance Test under C37.118.1a - 2014," in Proc. IEE PES Innovative Smart Grid Technologies Conference Europe (ISGT Europe), Ljubljana, 2016, pp. 1-6.

[37] M. S. Almas, J. Kilter, and L. Vanfretti, "Experiences with steady-state PMU compliance testing using standard relay testing equipment," in Proc. IEEE Electric Power Quality and Supply Reliability Conference (PQ), 2014, pp.103-110.
[38] K. Martin, T. Faris, and J. Hauer, "Standardized Testing of Phasor Measurement Units," in Proc. Fault and Disturbance Analysis Conference, Georgia Tech, Atlanta, GA, 2006.

[39] R. Garcia-Valle, G. Yang, K. E. Martin, A. H. Nielsen, and J Ostergaard, "DTU PMU laboratory development-Testing and validation," in Proc. Innovative Smart Grid Technologies Conference Europe (ISGT Europe), 2010, pp. 1-6.

[40] K.E. Martin, J.F. Hauer, and T.J. Faris, "PMU Testing and Installation Considerations at the Bonneville Power Administration," in Proc. IEEE PES General Meeting, Tampa, FL, 2007, pp. 1-6.

[41] K. Narendra, Z. Zhang, J. Lane, B. Lackey, and E. Khan, "Calibration and Testing of Tesla Phasor Measurement Unit (PMU) Using Doble F6150 Test Instrument," iREP Symposium-Bulk Power System Dynamics and Control -VII, Revitalizing Operational Reliability, August, 2007.

[42] Z. Huang, B. Kasztenny, V. Madani, K. Martin, S. Meliopoulos, D. Novosel, and J. Stenbakken, "Performance Evaluation of Phasor Measurement Systems," in Proc. IEEE PES General Meeting, Pittsburgh, PA, 2008, pp.1-7.

[43] P. Komarnicki, C. Dzienis, Z. A. Styczynski, J. Blumschein, and V. Centeno, "Practical experience with PMU system testing and calibration requirements," in Proc. IEEE PES General Meeting, Pittsburgh, PA, 2008, pp. 1-5.

[44] G. Stenbakken, and T. Nelson, "Static Calibration and Dynamic Characterization of PMUs at NIST," in Proc. IEEE PES General Meeting, Tampa, FL, 2007, pp 1-4.

[45] J. K. Hwang and Y. Liu, "Noise Analysis of Power System Frequency Estimated From Angle Difference of Discrete Fourier Transform Coefficient," IEEE Trans. on Power Del., vol. 29, no. 4, pp. 1533-1541, Aug. 2014.

[46] D. Macii, D. Fontanelli, G. Barchi, and D. Petri, "Impact of Acquisition Wideband Noise on Synchrophasor Measurements: A Design Perspective," IEEE Trans. Instrum. Meas., vol. 65, no. 10, pp. 22442253, Oct. 2016. 